\title{
INDÍGENAS KAINGANG DA COMUNIDADE FOXÁ, EM LAJEADO/RIO GRANDE DO SUL: Direito de Acesso aos Benefícios da Previdência Social
}

http://dx.doi.org/10.21527/2176-6622.2020.54.165-179

Recebido em: 20/5/2020

Aceito em: 26/6/2020

Luís Fernando da Silva Laroque Graduação em Estudos Sociais (1992) e em História (1996) pela Universidade do Vale do Rio dos Sinos (Unisinos1996). Mestrado em História (2000) e Doutorado em História (2006) pela Universidade do Vale do Rio dos Sinos (Unisinos). Professor da Universidade do Vale do Taquari (Univates) e professor da rede de ensino do Estado do Rio Grande do Sul. Trabalha com os seguintes temas: populações indígenas, cultura, etno-história, arqueologia, territorialidades, fronteiras, grupos étnicos, agricultura familiar, história ambiental, história regional e história do Brasil. http://lattes.cnpq.br/6550642682865922. https://orcid.org/0000-0003-1861-4679. Iflaroque@univates.br

Débora Pires Medeiros da Silva

Graduanda do Curso de Direito da Universidade do Vale do Taquari/RS (Univates). http://lattes.cnpq br/2367232920931225. https://orcid.org/0000-0003-4642-9411. debora.silva1@universo.univates.br

Fernanda Storck Pinheiro

Doutora em Direito pela Pontifícia Universidade Católica do Rio Grande do Sul (PUCRS, 2014). Mestre em Direito pela Universidade de Santa Cruz do Sul (Unisc, 2003). Graduada em Direito pela Universidade de Santa Cruz do Sul (Unisc, 2000). Professora do curso de Direito da Universidade do Vale do Taquari Univates. Professora colaboradora do Programa de Pós-Graduação em Ambiente e Desenvolvimento - PPGAD Mestrado e Doutorado da Univates. Tem experiência acadêmica na área de Direito, com ênfase em Direito e Processo do Trabalho nos seguintes temas: tutela coletiva, acesso à justiça e direitos fundamentais dos trabalhadores. Tem experiência profissional na área de Gestão Universitária. http://lattes.cnpq.br/2051002287550023. https://orcid.org/0000-0002-2521-5417.

RESUMO

fernandapinheiro@univates.br

O presente trabalho tem por base diálogo com um servidor do Instituto Nacional do Seguro Social (INSS) a respeito dos benefícios da Previdência Social requeridos por indígenas Kaingang. Os Kaingang, segundo o IBGE (BRASIL, 2012), correspondem a cerca de 38 mil pessoas aproximadamente e a comunidade estudada, denominada de Terra Indígena Foxá, localiza-se no contexto urbano do município de Lajeado/ RS. O objetivo deste estudo consistiu em identificar os desafios do acesso aos direitos da Previdência Social por integrantes da comunidade indígena Kaingang Foxá. Do ponto de vista metodológico tratou-se de uma pesquisa qualitativa e os procedimentos metodológicos consistiram em levantamento bibliográfico, documental e pesquisa de campo acerca do acesso aos direitos da Previdência Social por indígenas, a partir de relatos de um servidor do Instituto Nacional do Seguro Social (INSS). Por fim, contatou-se que não há benefícios previdenciários destinados aos Kaingang investigados devido a sua condição de índios, devendo essa população preencher os mesmos requisitos que os não índios quando na percepção de quaisquer benefícios da Previdência Social. Devido às atividades exercidas pelos indígenas, contudo, normalmente estes são enquadrados como segurados especiais, sendo a referida qualidade comprovada por meio da certidão emitida pela Funai que descreve a condição de índio e as atividades desenvolvidas.

Palavras-chave: Direito previdenciário. Previdência social. Instituto Nacional do Seguro Social (INSS). Indígenas. Kaingang.

\section{KAINGANG INDIGENOUS PEOPLE FROM THE FOXA COMMUNITY, FROM LAJEADO/RIO GRANDE DO SUL: RIGHT OF ACCESS TO SOCIAL SECURITY BENEFITS}

\section{ABSTRACT}

The article is based on dialogue with a National Institute of Social Security (INSS) server about the security benefits required by Kaingang indigenous people. The Kaingang, according to IBGE (2012), correspond to approximately 38,000 people and the Community studied, called "Terra Indígena Foxá", is located in the urban context of Lajeado/RS city. The aim of this study was to identify the challenges of access to Social Security rights by members of the Kaingang Foxá indigenous community. From the methodological point of view, this was a qualitative research and the methodological procedures consisted in a biographic, documental and field research on access to Social Security rights by indigenous peoples, based on reports from a National Institute of Social Security (INSS) server. Finally, it was found that there are no social security benefits for the Kaingang indigenous people investigated due to their indigenous status, and this population need to fill the same requirements as non-indigenous to receive any Social Security benefits. However, due to the activities performed by the indigenous people, these are framed as special insured, and this quality is proven through the certificate issued by Funai, which describes the condition of indigenous people and the activities developed.

Keywords: Social security law. Social security; National Institute of Social Security (INSS). Indigenous people. Kaingang.

\section{SUMÁRIO}

1 Introdução. 2 Histórico dos Kaingang no Rio Grande do Sul e no Município de Lajeado. 3 Previdência Social e as Comunidades Indígenas. 4 Requerimentos de Benefícios da Previdência Social com Relação aos Indígenas: relatos de um servidor do Instituto Nacional do Seguro Social (INSS). 5 Conclusão. 6 Referências. 


\section{INTRODUÇÃO}

$\mathrm{Na}$ atualidade, os Kaingang estão entre um dos maiores povos indígenas do Brasil, compreendendo cerca de 38 mil pessoas (BRASIL, 2012). Os grupos Kaingang estão distribuídos por quatro Estados brasileiros, quais sejam: Rio Grande do Sul, Santa Catarina, Paraná e São Paulo. A comunidade em análise encontra-se na área urbana de Lajeado, município do Vale do Taquari, no Estado do Rio Grande do Sul, e se chama Comunidade Kaingang "Foxá", cujo significado em Português faz referência às árvores de cedro presentes na aldeia, a qual possui em torno de 30 casas, que abrigam 32 famílias, compostas por aproximadamente 4 integrantes, correspondendo a um total de 128 pessoas.

Para que os dispositivos relacionados à Seguridade Social, mais especificamente à Previdência Social, bem como as normas estabelecidas na Constituição Federal e no Estatuto do Índio, sejam efetivos, é necessário que as comunidades indígenas compreendam seus direitos e deveres, principalmente no que se refere aos direitos da Previdência Social, tendo em vista que se trata de dispositivos que, geralmente, modificam-se rapidamente. O presente estudo busca responder ao seguinte questionamento: Quais os desafios do acesso aos direitos da Previdência Social na comunidade indígena Kaingang da Foxá com base em relato de servidor no INSS? Sabe-se que a legislação brasileira garante a proteção dos direitos das comunidades indígenas, bem como a preservação de suas culturas, costumes e tradições. Diante das dificuldades que a comunidade indígena Foxá enfrenta ao acessar os direitos previdenciários pode-se concluir que isso ocorre em razão da falta de políticas públicas que visem à conscientização indígena acerca dos direitos dessa natureza.

Pesquisas que abordam os direitos indígenas são poucos exploradas, evidenciando a falta de conhecimento e intensificando o preconceito existente a respeito dos índios. $O$ estudo acerca do desafio do acesso aos direitos da Previdência Social na comunidade Kaingang Foxá é relevante para a sociedade, pois irá evidenciar os direitos e as dificuldades que a comunidade Foxá enfrenta, servindo como fonte de informação, cuja finalidade é desconstruir preconceitos e pensamentos equivocados que muitos possuem quando se trata dos direitos dos índios.

Apesar de os índios serem os primeiros habitantes do Brasil, atualmente as comunidades indígenas possuem muitas dificuldades na garantia de seus direitos. Esse fato é possível identificar a partir de toda luta que esses povos enfrentaram e enfrentam para ver garantidos os dispositivos previstos na legislação brasileira, a qual, teoricamente, garante a proteção dos direitos das comunidades indígenas, bem como a preservação de suas culturas. Nesse sentido, o presente estudo propôs-se a identificar os desafios do acesso aos direitos da Previdência Social por integrantes da comunidade indígena Kaingang Foxá.

A metodologia utilizada foi do tipo qualitativo, sendo dedutiva e comparativa com relação ao método de abordagem e procedimento, respectivamente. Segundo Chemin (2015), o tipo de pesquisa qualitativa refere-se à investigação de percepções do público em estudo, o que será feito na comunidade Foxá, ao buscar qual a visão e experiências obtidas pelos indígenas ao requererem um benefício previdenciário. De acordo com Gil (2008), o método de abordagem dedutiva ocorre quando parte do geral para o particular e o método de procedimento comparativo se caracteriza quando há investigações de pessoas, destacando suas diferenças.

Por meio desses métodos foi realizada pesquisa de campo mediante um diálogo presencial com servidor do Instituto Nacional do Seguro Social, cuja intenção foi elucidar as dificuldades indígenas, particularmente da etnia Kaingang que também foi observada em incursões a campo, envolvendo os requerimentos de benefícios em via administrativa. $O$ estudo também utilizou instrumentos técnicos, tais como bibliográficos, documentais e pesquisa de campo.

\section{HISTÓRICO DOS KAINGANG NO RIO GRANDE DO SUL E NO MUNICÍPIO DE LAJEADO}

No século 19, mais especificamente no ano de 1824, começaram a chegar os primeiros imigrantes europeus. Referente aos alemães, estes se estabeleceram em regiões menos ocupadas pelos indígenas, observando-se que a imigração se manteve até meados de 1830, quando foi interrompida pela Guerra Farroupilha, movimento civil ocorrido entre os anos 1835 e 1845 (NONNENMACHER, 2000). 
Diante da vinda da imigração europeia, os colonos tentaram se aproximar dos territórios tradicionais dos Kaingang, contudo esses indígenas não demonstravam interesse pelo contato ou convivência com os brancos. Diante da política colonizatória em territórios do planalto gaúcho, conforme Becker (1975), o governo cogitava reunir e aldear os índios nos Aldeamentos de Guarita, Nonoai e Campo do Meio, pois, assim, haveria mais facilidade em controlá-los e, consequentemente, disponibilizar os territórios Kaingang aos colonizadores.

Em virtude do plano governamental, os indígenas eram deslocados para conviver em aldeias, pois apresentavam ameaça aos europeus. Enquanto isso, as terras indígenas eram tomadas cada vez mais pelos colonizadores (OLIVEIRA, 2010). Segundo Nonnenmacher (2000), o propósito do governo era de retirar os índios de suas terras a fim de que os europeus tivessem espaços para se estabelecer. Dessa forma, o indígena era forçado a se instalar em determinados locais, sendo esquecidos e expostos às condições de vulnerabilidades, assim como ocorre nos dias de hoje.

Pesquisas têm demonstrado que os antepassados Kaingang não mantinham muito contato com os colonizadores nos séculos 16, 17 e 18 pelo fato de viverem em territórios de planalto, os quais, em um primeiro momento, não despertaram maior interesse das frentes expansionistas. A partir do século 19 a situação muda e o contato com os não índios tornou-se mais frequente, tendo, em 1848, iniciado com os missionários (BECKER, 1975).

A partir de 1850, após a formação de aldeamentos, em especial o de Nonoai, os territórios Kaingang começaram a enfrentar transformações devido às ações dos colonos. A vinda dos europeus faz crescer o número de habitante nos municípios do Rio Grande do Sul, como Cruz Alta, que, posteriormente, em um de seus distritos, Passo Fundo, possui a sede de um importante aldeamento (NONNENMACHER, 2000). Nos primeiros contatos ocorriam muitas trocas de objetos, uma vez que, com a intenção de iniciar uma relação com os índios, sem que estes se opusessem à sua chegada, os europeus ofereciam presentes ao grupo, os quais, tomados como manifestação de alianças, eram aceitos (OLIVEIRA, 2010).

Becker (1975) descreve que os Kaingang são descendentes dos indígenas Guaianá e também podem ser identificados com outras denominações, como Bugres ou Coroados. A respeito da designação "Coroados", Mota (2004) destaca que esse foi um nome dado pelos portugueses, pelo fato de os Kaingang costumarem raspar o cabelo na parte superior da cabeça em forma de coroa, muito embora os indígenas não gostassem de serem chamado desta forma.

Ademais, Mota (2004, p. 14) justifica que essa atitude "[...] pode ter sido mais uma maneira de buscar dissolver a etnia Kaingang na população nacional, negando sua autodeterminação e sua identidade". Ainda assim, contudo, o grupo se defendeu e lutou contra a apropriação de suas terras e a suposta extinção da história brasileira.

De acordo com Tommasino e Fernandes (2001), a designação "Kaingang" foi inserida no contexto histórico ao final do século 19. Outrossim, cumpre informar que há controvérsias acerca de quem começou a utilizar esse nome para denominar o grupo indígena. Mota (2004), entretanto, informa que o termo Kaingang primeiramente foi utilizado pelo engenheiro Franz Keller em 1867 e o pelo sertanista Telêmaco Borba em 1882.

O termo Kaingang significa "povo do mato", a terra para os Kaingang possui grande importância. Para eles, a terra representa sua grande mãe, pois acreditam que surgiram através dela, por isso a comunidade tem uma ligação muito grande com seu território. Nas comunidades, a terra não serve somente para produzir riqueza, mas também para desenvolver suas práticas culturais (LAPPE; LAROQUE, 2018).

O grupo Kaingang pertence ao tronco linguístico Macro-Jê, família linguística Jê e atualmente possuem vários dialetos. Segundo D’Angelis (2006, p. 1-2), "[...] a língua Kaingang é uma das línguas com maior número de falantes entre as línguas indígenas do Brasil [...] como se espalharam por lugares tão distantes, há tanto tempo, os Kaingang desenvolveram vários dialetos diferentes".

A respeito da organização das aldeias e número de pessoas, Becker $(1975$, p. 104) ressalta que, inicialmente, "[...] viviam em pequenos agrupamentos organizados em aldeias; cada aldeia com seu chefe estava composta por 20 a 25 famílias, mas todas as aldeias estavam subordinadas a um cacique geral". Ademais, viviam em ranchos beira-chão, protegidos com folhas de palmeiras de tamanhos e figuras de acordo com quantidade de pessoas, condição e hierarquia da família (BECKER, 1975). 
De acordo com Tommasino e Fernandes (2001), "[...] pode-se relacionar a expansão geográfica dos Kaingang com as pressões que as expedições de conquista foram promovendo". Nesse período, além do plano governamental, muitos caciques tornaram-se aliados dos brancos e coagiam os grupos a formarem aldeias em lugares mais retirados. Dessa forma, parte dos territórios era liberada aos europeus colonizadores.

Inicialmente, a economia desse grupo foi organizada por meio da caça, pesca, coleta de frutas e agricultura. Segundo Veiga (2006), "A caça incluía os grandes e pequenos mamíferos das florestas subtropicais [...] usavam mais frequentemente caçar aves e animais com seus arcos e flechas, com diferentes tipos de pontas feitas de madeira ou ossos de animais".

Com relação aos costumes e práticas de rituais, os Kaingang possuem a cosmologia muito presente em sua cultura. Uma das práticas culturais desse grupo trata-se da forma que se constitui o matrimônio, o qual é feito por um sistema de metades. Essa cultura determina que o casal seja formado por um Kamé, o qual representa o sol, e um Kaiâru, que representa a lua. Os casamentos devem ser realizados com pessoas de metades opostas. Os Kamé são apontados como tendo espíritos mais fortes, já os Kaiâru tomam a frente em questões que envolvam política e guerras (VEIGA, 2004).

A esse respeito, este autor (2004) relata:

Diferentes dos Jê setentrionais e populações indígenas não implica trocas matrimoniais, o dualismo Kaingang inclui a exogamia de metades. Os Kaingang percebem o mundo como perfeitamente simétrico, formado por pares antitéticos e complementares. Esse princípio formador do mundo é personificado nos heróis míticos Kamé e Kaiâru, homônimos das metades Kaingang. Os Kaingang afirmam que o sol é Kamé e a lua é Kaiâru (cf. Nimuendajú [1913] 1993, p. 60), embora não assumam, nem seus mitos enunciem, que as metades sejam sol e lua, como é comum a outros povos Jê. A relação de troca entre as metades é permanente. Casa-se na metade oposta, enterram-se os mortos da outra metade e, quando alguém passa por um período de liminaridade, é acompanhado e servido por pessoas da metade oposta à sua (VEIGA, 2004, p. 269).

Ainda a respeito do sistema cosmológico dualista, Ferreira (2014, p. 37) leciona que "[...] cada metade clânica possui uma marca/sinal que usa em seus rituais: a dos Kamé é téj (comprido), a dos Kaiâru é ror (curto). As pessoas da mesma marca são consideradas irmãs e irmãos". Assim, os Kamé são representados pelo símbolo de listras e os Kaiâru por bolinhas (Figura 1). Além disso, as crianças herdam a marca do pai, independentemente do gênero (FERREIRA, 2014). Segundo Prestes e Laroque (2018, p. 32), "a concepção destas metades remonta ao mito de origem dos Kaingang, que está ligado à crença da procedência do povo a partir da terra".

Figura 1 - Jovens Kaingang com os sinais que representam Kamé (listras) e Kaiâru (bolinhas)

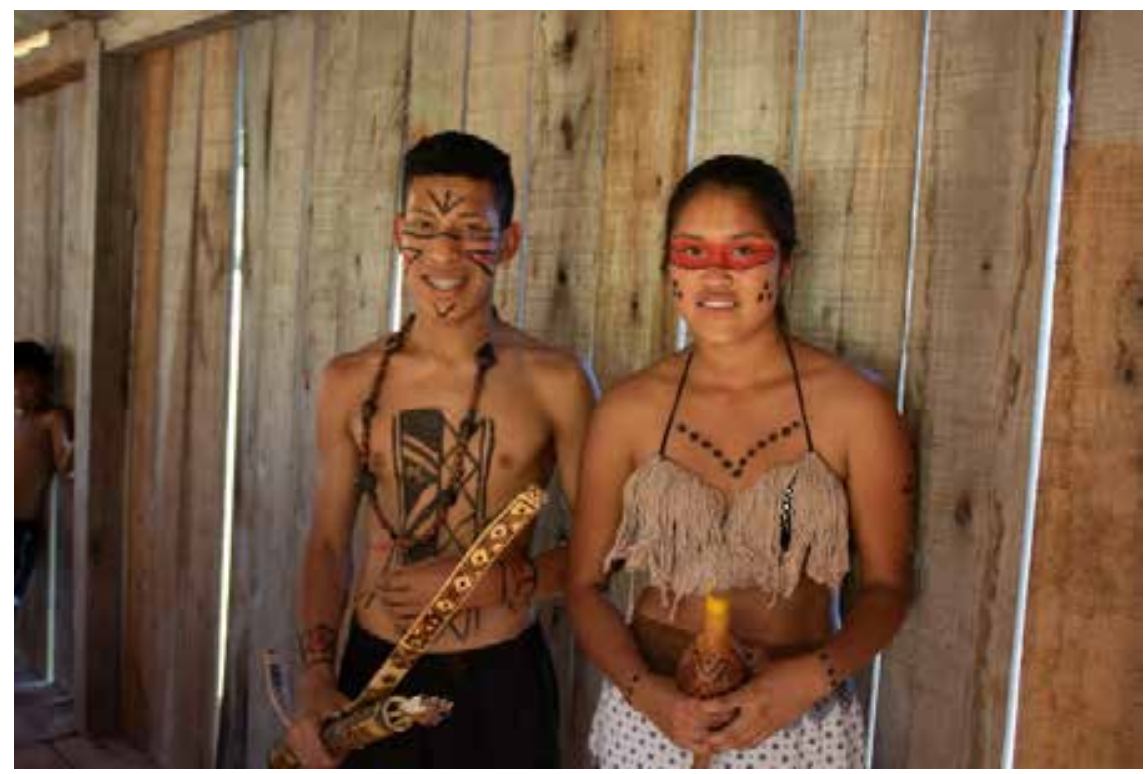

Fonte: Acervo do Projeto. 
Ademais, os Kaingang dão grande importância aos antepassados, aos mortos e, principalmente, para a terra onde estão enterrados (TOMMASINO; FERNANDES, 2001). Para os Kaingang, quando uma pessoa de sua comunidade falece, ela apenas passa para uma aldeia que se encontra em outra dimensão, a qual possui tempo e condições sempre opostas às nossas, ou seja, se aqui está com um tempo chuvoso, lá está sol, se aqui é dia, lá é noite (VEIGA, 2004).

Uma das principais expressões cultural dos Kaingang trata-se de um ritual com relação aos mortos. Tommasino e Fernandes (2001) ressaltam que "[...] o culto aos mortos destaca-se não apenas pela importância atribuída pelos Kaingang, mas também, por seu caráter comunitário e intercomunitário". A esse ritual dá-se a denominação de "Festa do Kikikoi".

A festa do Kikikoi, segundo Veiga (2004, p. 273), "[...] trata-se de uma festa para os mortos recentes, que é organizada pelos consanguíneos do morto, em sua homenagem". Para realização da festa é necessário todo um processo para a preparação da bebida "Kiki", a qual é uma espécie de cerveja que dá nome ao evento. Esse ritual, feito em homenagem aos mortos, é também o momento em que são liberados os nomes para serem usados nas crianças (FERREIRA, 2014).

Com relação a Lajeado, onde a TI Foxá está localizada, destaca-se que esta fazia parte de uma colônia denominada de "Colônia Conventos", a qual, entre os anos de 1794 e 1856, passou por dois proprietários, os irmãos descendentes de açorianos, oriundos de Laguna, chamados João Ignácio Teixeira e José Ignácio Teixeira. Os irmãos receberam a propriedade por meio das sesmarias no ano de 1794 , que mediante uma sociedade buscavam aumentar seus domínios territoriais (GREGORY, 2015). De acordo com Vedoy (2018), posteriormente, as terras foram ocupadas pelos imigrantes alemães.

No ano de 1891 Lajeado se desmembrou do município de Estrela, do qual fazia parte, e no dia 26 de janeiro de 1891 tornou-se um município. Atualmente Lajeado faz parte do Vale do Taquari, região central do Estado do Rio Grande do Sul, e possui aproximadamente 85.000 habitantes (BRASIL, 2019c). Além dos Kaingang, o município é composto por imigrantes e descendentes de alemães, além de italianos, africanos, portugueses, mais recentemente de haitianos e senegaleses. O município possui sua economia baseada no comércio, na indústria de transformação, de beneficiamento e serviços (LAJEADO, 2019).

Diante do plano colonizador, os ancestrais dos Kaingang tiveram os seus territórios dominados pelos imigrantes alemães e italianos. Conforme descrito anteriormente, nessa oportunidade o governo seguia com o confinamento do grupo indígena em grandes aldeamentos no Norte do Rio Grande do Sul. Os Kaingang, contudo, começaram a sair desses grandes aldeamentos e a retornar para as áreas que já pertenciam aos seus antepassados, ressaltando-se que este é um costume muito presente nas comunidades indígenas. Ao final do século 20, mais especificamente entre os anos 90 e o início dos anos 2000, muitos indígenas intensificaram as movimentações de retorno para o Vale do Taquari e se alojaram no município de Lajeado (LAPPE; LAROQUE, 2018).

A respeito das lutas pelos territórios que sempre pertenceram aos Kaingang, Lappe e Laroque (2018) observam:

Entende-se que a luta pela terra se torna uma luta pela manutenção da identidade étnica, baseada em uma cultura e memória em comum, pois as terras tradicionalmente ocupadas pelos Kaingang configuram-se como transmissão cultural, um direito originário e preexistente à ocupação ocidental, para a proteção efetiva do presente, que objetiva a garantia do futuro, no sentido de que essas terras estão para sempre destinadas a ser hábitat permanente das populações indígenas (LAPPE; LAROQUE, 2018, p. 29).

A comunidade em análise, a qual se denomina "Foxá", encontra-se na área urbana de Lajeado, município do Vale do Taquari, no Estado do Rio Grande do Sul. Essa comunidade formou-se há aproximadamente 20 anos e, desde então, busca recuperar seus tradicionais territórios. Destaca-se que os primeiros indígenas que retornaram para a cidade de Lajeado são de famílias provenientes de Nonoai, Serrinha, Votouro e Guarita (LAPPE; LAROQUE, 2018). 
Ao retornarem, aproximadamente 15 pessoas estabeleceram-se às margens da RS130, próximo ao Presídio Estadual e à Rodoviária de Lajeado. Nesse período, os indígenas permaneceram no local, buscando por seus direitos, apesar de todo perigo presente no lugar (PRESTES; LAROQUE, 2018). Segundo Lappe e Laroque (2018), os indígenas tinham interesse em comercializar seus artesanatos para subsidiar a compra de alimentos, roupas e material escolar para as crianças e jovens estudantes.

No ano de 2003 iniciaram-se discussões a respeito das circunstâncias em que as famílias indígenas de Lajeado se encontravam, observando-se que as autoridades que tomaram a frente foram a Promotoria de Justiça, Assistência Social e os secretários municipais. Na oportunidade foi sugerido que os indígenas tivessem um lugar para se estabelecer enquanto estivessem na cidade. Assim, em 2004, os órgãos públicos e os representantes dos indígenas Kaingang realizaram uma reunião para firmarem melhores condições aos índios do município (LAPPE; LAROQUE, 2018).

Em nova reunião, também no ano de 2004, ficou decidido que a Fundação Nacional da Saúde (Funasa) providenciaria a instalação do ponto de água no acampamento da RS130, posto que essa situação era um dos principais problemas enfrentados pelos Kaingang. No mesmo ano também foi sugerida a troca do acampamento para um local de $500 \mathrm{~m}^{2}$ também às margens da RS-130, distante aproximadamente $2 \mathrm{~km}$ do trevo de acesso, no sentido Lajeado-Cruzeiro do Sul. Somente após muitas reuniões os Kaingang vieram a receber a área de terras localizada no bairro Jardim do Cedro (LAPPE; LAROQUE, 2018).

No ano de 2005 foi autorizada a Cessão de Uso das terras e os indígenas conseguiram o direito de ocupar uma área de $525 \mathrm{~m}^{2}$ por meio do "Termo Administrativo de Cessão de Uso celebrado entre a prefeitura de Lajeado e a Secretaria do Trabalho, Cidadania e Assistência Social do Estado do Rio Grande do Sul" (LAPPE; LAROQUE, 2018, p. 35). Em 2006 o local foi disponibilizado e, em 2007, foi decidida a construção de casas para as famílias Kaingang. No mesmo ano foram construídas oito casas, três sanitários e dois tanques para lavar roupa com materiais doados pela Companhia Estadual de Energia Elétrica (Ceee) e pela prefeitura, além de instalação de água e luz com recursos da Funasa e do governo federal (LAPPE; LAROQUE, 2018). Logo que se estabeleceram no local atual (Figura 2) os indígenas escolheram um nome para a comunidade. $O$ nome escolhido, conforme já referido, foi "Foxá", que faz referência às arvores de cedro presentes na aldeia (LAPPE; LAROQUE, 2018).

Figura 2 - Aldeia Foxá localizada no bairro Jardim do Cedro

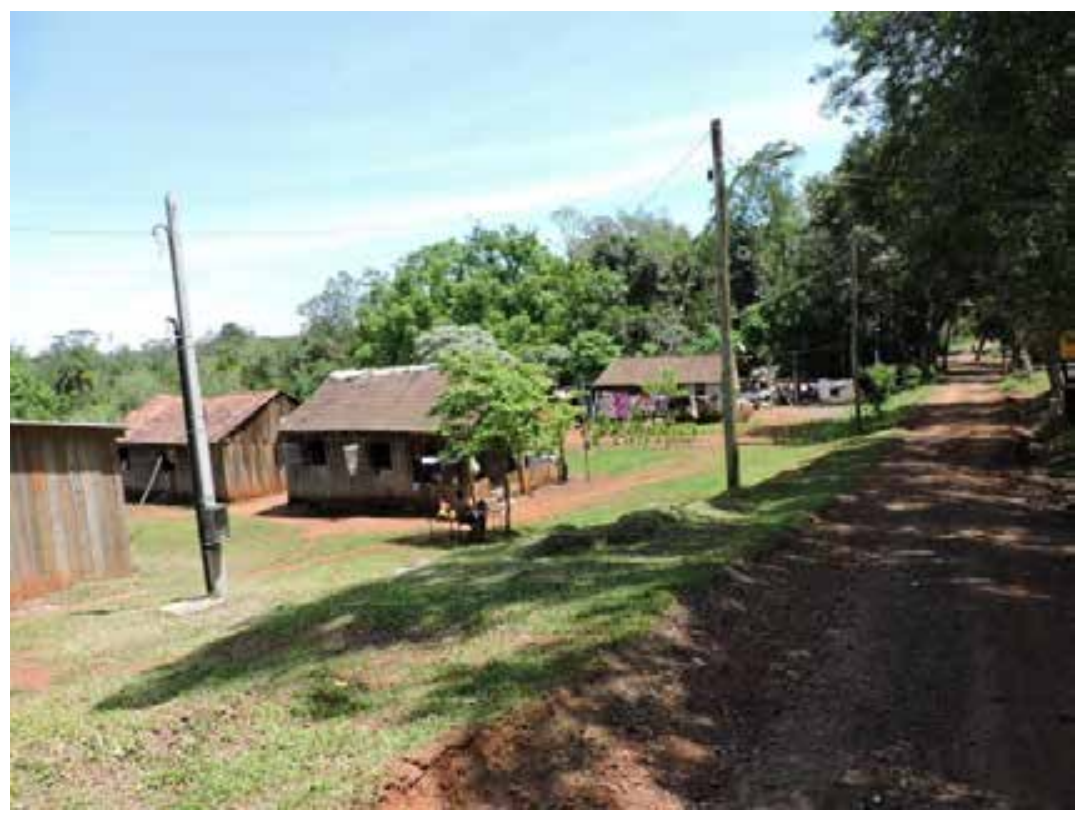

Fonte: Acervo do Projeto.

Acerca das terras onde atualmente está estabelecida a TI Foxá, Prestes e Laroque (2018, p. 33) descrevem que se trata de "[...] um lugar mais tranquilo, que conta com uma pequena mata, onde é possível coletar frutos e materiais para a confecção do artesanato". Atualmente a comunidade conta com mais casas, as quais 
foram construídas pelos próprios indígenas (PRESTES; LAROQUE, 2018). A aldeia possui aproximadamente 30 casas com cerca de 32 famílias, as quais, conforme já referido, são integradas por quatro membros aproximadamente, totalizando, atualmente, em torno de 128 pessoas.

O artesanato (Figuras 3 e 4) é uma das principais fontes de renda dessa comunidade, contudo alguns indivíduos optaram por trabalhar em empresas da região devido às dificuldades econômicas enfrentadas pela comunidade. Cada família conta com pelo menos um membro trabalhando em empresas locais. Essa renda tem auxiliado no sustento de cada grupo, uma vez que não há recursos suficientes somente com a produção de artesanatos (PRESTES; LAROQUE, 2018).

Figuras 3 e 4 - Artesanatos produzidos por moradores da Aldeia Foxá
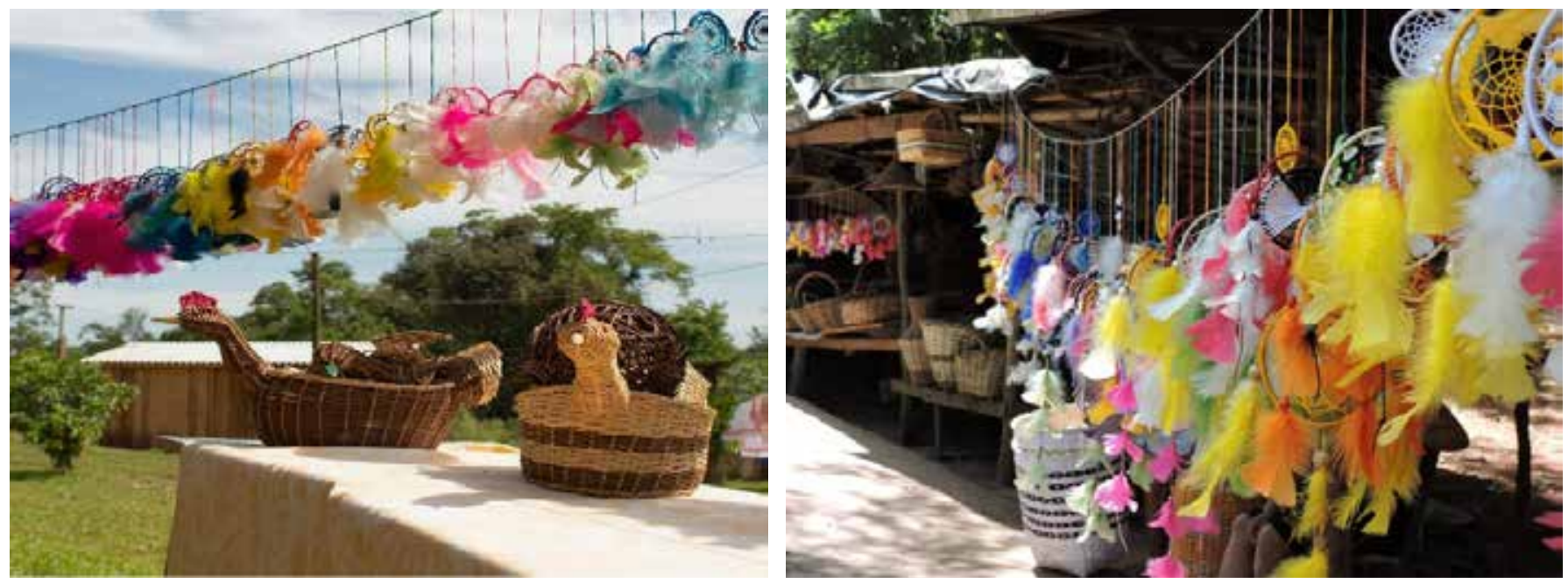

Fonte: Acervo do Projeto.

Referente à educação, a comunidade indígena Foxá possui uma pequena escola na aldeia, a qual se denomina Escola Estadual Indígena de Ensino Fundamental Gatén, que na língua portuguesa significa "espírito da terra" (PRESTES; LAROQUE, 2018). As crianças permanecem no local até a 5a série (Figura 5), aprendem sobre a língua e os ensinamentos da cultura Kaingang e, posteriormente, passam a frequentar as escolas dos não indígenas.

Figura 5 - Escola Gatén na Aldeia Foxá

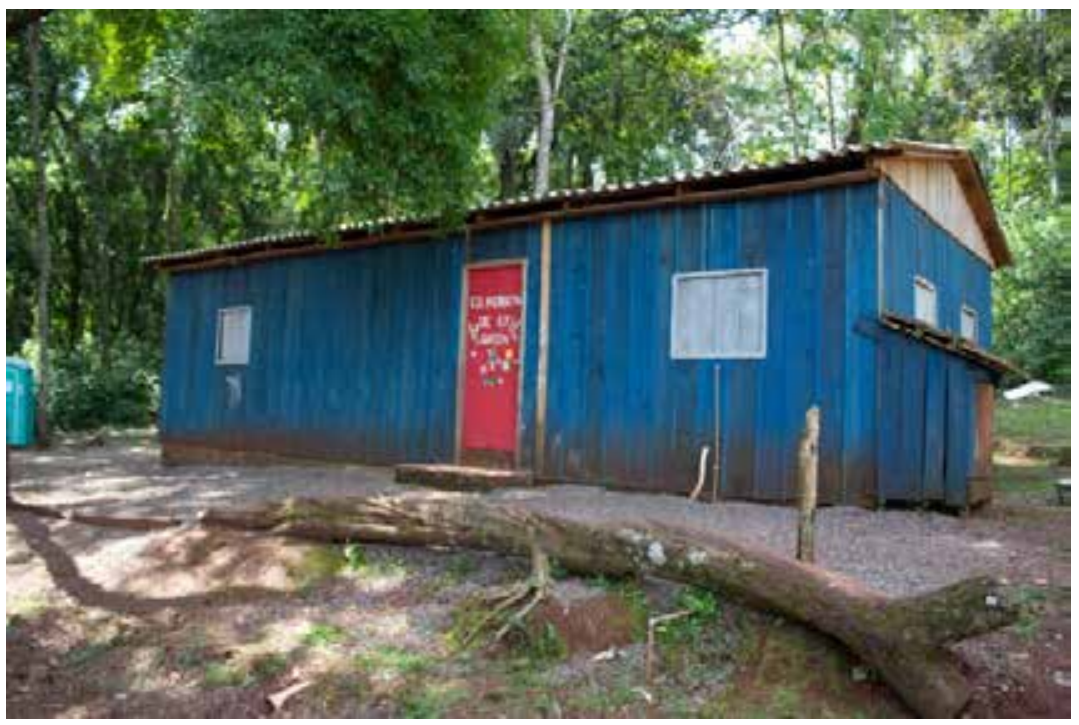

Fonte: Acervo do Projeto. 
Atualmente as lideranças da comunidade indígena Kaingang Foxá são representadas nas pessoas de Joel Vergueiro, cacique, e por Jucelino Sales, vice-cacique. A aldeia também conta com pessoas que auxiliam as ações das lideranças. As terras da aldeia ainda encontram-se pendentes de regularização, contudo os representantes estão se dedicando a reverter esse quadro.

Cumpre ressaltar que grande parte dos indígenas da comunidade trata-se de pessoas jovens e crianças. Os mais velhos sempre demonstram empenho para que as culturas Kaingang se perpetuem nas próximas gerações. É possível identificar o respeito e a preservação da cultura Kaingang, apesar de todo preconceito e adversidades que o grupo enfrenta em uma sociedade predominantemente de descendentes de europeus, como a cidade de Lajeado/RS.

A aldeia é muito organizada e sua liderança sempre está ciente e trata de todos os assuntos, principalmente as questões relacionadas aos direitos da comunidade. Em que pese tenha havido melhoras desde a vinda das primeiras famílias, o lugar e as pessoas ainda necessitam de atenção especial, principalmente das autoridades locais.

Assim, é possível identificar que os representantes da comunidade Kaingang Foxá estão sempre em busca de melhorias que promovam o desenvolvimento e o alcance dos interesses da comunidade. Dessa forma, é de suma importância que as autoridades se voltem para o grupo e assegurem os direitos básicos previstos na legislação brasileira, pelos quais todas as comunidades indígenas têm lutado diariamente e reivindicado sua efetividade .

\section{PREVIDÊNCIA SOCIAL E AS COMUNIDADES INDÍGENAS}

A Seguridade Social, expressa no Capítulo II da Constituição Federal de 1988, é composta pelo direito à saúde, à assistência social e à Previdência Social. Os benefícios que abrangem o sistema da Previdência Social do Regime Geral da Previdência Social (RGPS) constituem um dos três ramos da Seguridade Social.

O conceito da Seguridade Social está previsto no artigo 194 da CF/88, o qual descreve que "[...] compreende um conjunto integrado de ações de iniciativa dos poderes públicos e da sociedade, destinadas a assegurar os direitos relativos à saúde, à previdência e à assistência social" (BRASIL, 1988). Freitas (2016, p. 48) relata que "[...] é um sistema de proteção social avançado e foi reconhecido pelo artigo 22 da Declaração Universal dos Direitos Humanos, de 1948, como um direito fundamental".

A Previdência Social está regulamentada na seção III da CF/88, mais especificamente nos artigos 201 e 202, além de outros dispositivos, como as Leis $n^{\circ} 8.212$ e 8.213 de 1991 e o Regulamento da Previdência Social criado pelo Decreto no 3.048, de 6 de maio de 1999. Em seu Regulamento, a partir do artigo 4o, é possível identificar os objetivos que regem esse sistema.

Castro e Lazzari (2016) descrevem que, além de ser regulada pelos princípios da CF/88 e da Seguridade Social, a Previdência Social também possui princípios específicos que a regulamentam. Os regimes da Previdência Social estão previstos no artigo 6ㅇ de seu Regimento, e compreendem o Regime Geral de Previdência Social (RGPS), o Regime Próprio de Previdência Social (RPPS), além do Regime de Previdência Complementar (RPC) (BRASIL, 1999). O primeiro é exercido por meio da autarquia federal Instituto Nacional do Seguro Social (INSS), no qual "[...] dentre os contribuintes, encontram-se os empregadores, empregados assalariados, domésticos, autônomos, contribuintes individuais e trabalhadores rurais" (BRASIL, 2013).

O segundo é executado pelo Ministério da Previdência Social, sendo destinado a servidores públicos e militares, mas "[...] excluem-se deste grupo os empregados das empresas públicas, os agentes políticos, servidores temporários e detentores de cargos de confiança, todos filiados obrigatórios ao Regime Geral" (BRASIL, 2013). E, por fim, o terceiro possui as políticas elaboradas pelo Ministério da Previdência Social, contudo é executado pela Superintendência Nacional de Previdência Complementar e "[...] tem por finalidade proporcionar ao trabalhador uma proteção previdenciária adicional àquela oferecida pelo Regime Geral de Previdência Social - RGPS - ou pelo Regime Próprio de Previdência Social - RPPS" (BRASIL, 2013).

A Previdência Social, com relação ao Regime Geral de Previdência Social, sobre o qual se delimita o presente estudo, possui "[...] caráter contributivo e filiação obrigatória, observados critérios que preservem o equilíbrio financeiro e atuarial" (FREITAS, 2016, p. 53). Os segurados são caracterizados no artigo 9o do 
Regulamento da Previdência Social e podem ser classificados como obrigatórios ou facultativos. Com relação aos segurados obrigatórios podemos mencionar o empregado, o empregado doméstico, trabalhador avulso, contribuinte individual e o segurado especial.

Trata-se de segurado empregado todos que "[...] trabalham de carteira assinada, contrato temporário, diretores-empregados, que têm mandato eletivo, que prestam serviço a órgãos públicos em cargos de livre nomeação e exoneração [...], que trabalham em empresas nacionais instaladas no exterior" (BRASIL, 2017b). Na comunidade Foxá é possível identificar que quando os moradores não são enquadrados como segurados especiais é porque se trata de empregados das empresas locais.

Por outro lado, existem os trabalhadores avulsos, os quais correspondem aos trabalhadores que prestam serviços para várias empresas e são contratados por sindicatos de sua categoria (BRASIL, 2009). Os empregados domésticos são aqueles que trabalham em casas de outra pessoa ou família, cuja atividade não proporciona fins lucrativos ao empregador, conforme disciplinado pela Lei Complementar 150 de 2015 (BRASIL, 2015b).

O contribuinte individual é aquele que trabalha por conta própria, sem vínculo empregatício. O segurado especial consiste na pessoa que desenvolve atividades que constitua seu principal meio de vida, tais como o produtor rural, o filho maior de 16 anos a esse equiparado, pescador artesanal ou a esse assemelhado e o índio (BRASIL, 2017b). Insta ressaltar que esse enquadramento corresponde à grande maioria dos moradores da Aldeia Foxá em razão das atividades desenvolvidas.

Santos (2018) ressalta que, para ter direito aos benefícios da Previdência Social, é indispensável que a pessoa seja segurada. Assim, as principais características desse sistema é a filiação prévia, proteção precípua do trabalhador e a contributividade, isto é, o indivíduo deverá ser filiado, evitando-se filiações de pessoas que se encontram incapazes, bem como deverá ocorrer a proteção previdenciária das atividades laborativas e, consequentemente, a contribuição ao sistema (FREITAS, 2016).

Com relação aos direitos previdenciários que se referem aos índios, destaca-se que "[...] os indígenas são cidadãos plenos, e têm direito aos benefícios sociais e previdenciários do Estado Brasileiro" (BRASIL, 2019b). Em 1973 o Estatuto do Índio já concedia aos indígenas direitos da Previdência Social. Da mesma forma, no ano de 2004 a Convenção no 169 da OIT também reforçou a garantia dos direitos da seguridade social aos indígenas. Entre os principais podem ser citados os benefícios de aposentadoria voluntária com o cumprimento de tempo de contribuição, aposentadoria por invalidez, aposentadoria especial, pensão por morte, aposentadoria por idade, salário-maternidade, entre outros, todos eles previstos no artigo 18 da Lei 8.213/91.

Os indígenas que trabalham e, consequentemente, estão vinculados ao Regime Geral da Previdência Social (RGPS), possuem os mesmos direitos dos demais trabalhadores do Brasil, independentemente de viverem isolados, em terras indígenas ou em regiões urbanas. Na Aldeia Kaingang Foxá, localizada no município de Lajeado, há diversas pessoas que trabalham em empresas locais, como Cia. Minuano de Alimentos e BRF S.A. Neste caso, os indígenas que trabalham em empresas, como as referidas anteriormente, acabam se enquadrando como empregados. Assim como o não índio, os indígenas ainda podem se enquadrar como segurados especiais. Isso ocorre quando eles exercem atividades relacionadas à agricultura, pesca e artesanato, desde que seja atividade rural individual ou em regime de economia familiar, conforme prevê o artigo 39 , $\S 4^{\circ}$ da Instrução Normativa 77/2015 do INSS.

Além disso, seus dependentes também possuem direitos em caso de ausência do segurado, de acordo com o artigo 16 da Lei $n^{\circ} 8.213 / 91$. Cumpre ressaltar que os índios não possuem direitos aos benefícios da Previdência Social em razão de sua condição, pois lhes são garantidos quaisquer dos benefícios desse sistema, desde que cumpridos todos os requisitos legais. Em que pese, contudo, o direito esteja previsto e a intenção do legislador seja de assegurar as garantias indígenas, cabe ressaltar que os índios encontram muitas dificuldades com o meio probatório para a concessão de benefícios, principalmente com relação aos segurados especiais, que representam boa parte da Aldeia Foxá, os quais vivem praticamente do artesanato.

Nesse sentido, Freitas (2016) descreve que em diversos casos a certidão emitida pela Funai, documento hábil para comprovar a qualidade de segurado especial, não é o suficiente, tendo em vista que durante o cruzamento de dados ocorrem divergências no seu preenchimento, além de muitos indígenas acabarem laborando por curtos períodos em empresas, o que descaracteriza a atividade especial. Exemplificando, pode-se utilizar uma situação trazida pelo autor, o qual descreve que "[...] se o indígena tiver trabalhado por três anos, 
por exemplo, como segurado empregado e o restante do seu tempo como trabalhador rural, não poderá ter a redução de cinco anos para a aposentadoria por idade, cabendo buscar a aposentadoria mista" (FREITAS, 2016, p. 59).

De acordo com o artigo 18 da Lei n 8.213/91, os benefícios do Regime Geral de Previdência Social são os seguintes: aposentadoria por invalidez; aposentadoria por idade; aposentadoria voluntária com o cumprimento de tempo de contribuição; aposentadoria especial; auxílio-doença; salário-família; salário-maternidade; auxílio-acidente e, com relação aos dependentes, há a pensão por morte e o auxílio-reclusão, além do serviço social e a reabilitação profissional que será concedida tanto para o segurado como para os dependentes (BRASIL, 1991). Referente aos indígenas, em cada uma dessas categorias os requisitos a serem preenchidos são os mesmos que para as demais pessoas, devendo o servidor da autarquia, em casos de requerimentos administrativos, ou os juízes, em casos de pedidos judiciais, observar as particularidades desses povos.

Dessa forma, a população indígena poderá se enquadrar em qualquer das categorias dos benefícios da Previdência Social, em que pese, normalmente, esteja enquadrada como segurado especial devido as suas atividades. Destaca-se que não existem privilégios nem benefícios destinados aos indígenas devido a sua condição étnica, ao contrário do que o senso comum e pessoas desavisadas pensam.

É fundamental que se trate a respeito da Previdência Social com relação aos indígenas, pois, conforme já mencionado anteriormente, devido à situação econômica do Brasil, os benefícios têm sido cada vez mais restritos à população. Assim, se o acesso aos direitos da Previdência Social está difícil para as demais pessoas, para os indígenas mostra-se ainda pior, uma vez que esse grupo merece atenção especial, pois se trata de um povo em situação de vulnerabilidade social, que, muitas vezes, não tem o conhecimento e condições de acesso -aos seus direitos, sendo necessária a promoção da inclusão social e de políticas públicas que visem a sanar esse problema social. Por fim, destaca-se que é de suma importância que se aborde esse tipo de temática, visando à conscientização dos povos indígenas quanto à evolução de seus direitos, principalmente com relação aos dispositivos da Previdência Social, uma vez que se tratam de leis complexas, que frequentemente passam por reformulações.

\section{REQUERIMENTOS DE BENEFÍCIOS DA PREVIDÊNCIA SOCIAL: Relatos de um Servidor do Instituto Nacional do Seguro Social (INSS)}

Para melhor entendimento de como é a prática dos requerimentos no INSS feitos pelos indígenas da Aldeia Foxá, posto que, muitas vezes, a prática difere da teoria, entendeu-se necessário investigar como ocorre o acesso selecionando um Instituto Nacional do Seguro Social (INSS). Na agência do INSS em questão, em diálogo com um servidor, obteve-se a informação de que não há muitos indígenas que procuram os benefícios da Previdência Social na agência de Lajeado. Informou que é possível que na agência de Estrela, município próximo e onde também existe uma aldeia indígena Kaingang em contexto urbanos, talvez tenha mais procu$\mathrm{ra}$, tendo em vista que a comunidade indígena daquele município é maior (DIÁRIO DE CAMPO, 2019b).

Essa informação corrobora o entendimento de que os índios da Aldeia Foxá acabam não usufruindo dos direitos que thes cabe por lei, seja por falta de conhecimento ou pela própria burocracia do mundo não índio. Esse fato foi identificado por meio do relato de uma interlocutora da aldeia pesquisada, a qual informou que um morador Kaingang da Comunidade Foxá recebeu benefício durante sete anos, pois tinha problemas na coluna, contudo, em perícia de revisão, o Instituto Nacional do Seguro Social (INSS) negou a continuidade do pagamento de seu benefício. Após algumas tentativas de restabelecimento do benefício o morador desistiu de solicitar diante da burocracia que precisou enfrentar (DIÁRIO DE CAMPO, 2019b).

Um servidor do Instituto Nacional do Seguro Social (INSS) com quem se dialogou afirmou que "normalmente o índio é enquadrado como segurado especial, que é comprovado através de declaração emitida pela Funai certificando a condição indígena como trabalhador rural" (DIÁRIO DE CAMPO, 2019b, p. 2). Ademais, informou, e vale enfatizar novamente, que não existe benefício destinado ao índio somente devido a sua condição étnica. Além disso, alegou que o indígena é enquadrado como segurado especial devido à semelhança de suas atividades com a dos agricultores e pescadores, por exemplo. Aqueles, no entanto, que laboram em atividades urbanas têm dificuldades de poder valer-se desse enquadramento, ou seja, são definidos como empregados (DIÁRIO DE CAMPO, 2019b). 
A respeito dos documentos probatórios dos segurados especiais, um servidor do Instituto Nacional do Seguro Social (INSS) informou que a certidão fornecida pela Funai, certificando a condição do índio como trabalhador rural, nos termos do artigo 47, inciso XI da Instrução Normativa do INSS de 2015, é o suficiente para comprovação e enquadramento do segurado especial (DIÁRIO DE CAMPO, 2019b), entretanto "a autarquia não estará vinculada aos documentos, podendo concordar ou não com as informações descritas, principalmente em casos de divergência no momento do cruzamento de dados" (DIÁRIO DE CAMPO, 2019b, p. 2). Acerca da vinculação da autarquia com os documentos fornecidos pela Funai a legislação assim prevê:

Art. 119. Os períodos de atividades do cadastro do segurado especial serão submetidos a cruzamento com outros bancos de dados a que o INSS tenha acesso, para fins da validação prevista no art. 329-B do RPS.

§1ㅇ Do cruzamento das informações, referidas no caput, poderá resultar na consideração ou desconsideração do período de atividade, caracterizando ou não a condição de segurado especial, respeitado o disposto na Seção VI do Capítulo I.

§2ㅇ Constando registro de óbito no sistema informatizado de óbitos, o período formado será encerrado no dia anterior à data desta ocorrência (BRASIL, 2015a).

A respeito da obtenção das informações para o preenchimento dessas certidões, a Instrução Normativa 77 do INSS de 2015, em seu artigo 118 descreve o seguinte:

Art. 118. As informações obtidas pelo INSS dos bancos de dados disponibilizados por órgãos do poder público estão sendo utilizadas para a construção do cadastro do segurado especial, para fins de reconhecimento dessa atividade.

§10 As informações referidas no caput observarão critérios de utilização e valoração definidos por meio de resolução específica.

§2ㅇ Os dados da Fundação Nacional do Índio - Funai - são obtidos por meio de inscrição e certificação dos períodos de exercício de atividade do indígena na condição de segurado especial, que são realizadas por servidores públicos desta Fundação, mediante sistema informatizado disponibilizado no sítio da Previdência Social, nos termos do Acordo de Cooperação Técnica celebrado entre o Ministério da Previdência Social e Ministério da Justiça, INSS e Funai.

§3 A Funai deverá manter sob sua guarda e responsabilidade os documentos que serviram de base para a inscrição e certificação dos períodos de exercício da atividade, podendo o INSS solicitá-los a qualquer momento (BRASIL, 2015a).

Conforme abordado, é nesse cruzamento de dados que diversos índios encontram dificuldades para o seu enquadramento, pois muitos deles trabalham ora em atividades rurais, ora em atividades urbanas. Inclusive, é possível reforçar tal assertiva após diálogo com um indígena da Aldeia Foxá que relatou trabalhar por muitos anos em uma das empresas de frigorífico local, porém anteriormente atuou como agricultor na aldeia de Nonoai (DIÁRIO DE CAMPO, 2019a). Dessa forma, deve ser considerada toda a dinâmica da cultura indígena e os costumes de transição pelas terras de seus antepassados, como fazem os Kaingang. Esse fator pode ocorrer principalmente quando o índio se muda de uma aldeia/município para outra(o) e passa a desenvolver atividades diversas.

Ao servidor foi perguntado acerca do funcionamento das contribuições, pois se sabe que "a forma de contribuição para o INSS no caso de segurado especial corresponde ao percentual de $2,3 \%$ incidente sobre o valor bruto da comercialização da sua produção rural" (BRASIL, 2017a). Além disso, tem-se conhecimento de que o recolhimento dessa tributação ocorre quando o produtor rural vende seus produtos para uma empresa e, posteriormente, esta fica responsável em descontar tal recolhimento repassando-o ao INSS (BRASIL, 2017a). O servidor esclarece que essa contribuição não é decisiva para a concessão do benefício, pois na análise do requerimento do benefício a informação de recolhimento da tributação não é levada em consideração. Ademais, ele informa que o "[...] segurado especial, como o agricultor, faz a comprovação de sua atividade através de vários documentos. Um dos principais é o talão de produtor rural [...] que nos casos de segurado especial não há necessidade de contribuição direta" (DIÁRIO DE CAMPO, 2019b, p. 2). 
Sobre a questão do valor da tributação, o servidor relata que a reforma da Previdência Social, por meio da PEC $n^{\circ}$ 06/2019, tentou majorar a contribuição sobre os produtos vendidos pelo segurado especial para $5 \%$, contudo o texto foi retirado em uma das votações, sendo mantidos os 2,03\% (DIÁRIO DE CAMPO, 2019b). Impende informar que essa tributação compreende em "2,0\% para a Seguridade Social; 0,1\% para financiamento dos benefícios concedidos em razão do grau de incidência de incapacidade laborativa decorrente dos riscos ambientais do trabalho (SAT) e 0,2\% para o Senar (Serviço Nacional de Aprendizagem Rural)" (BRASIL, 2017a).

O servidor com o qual estabelecemos a interlocução ainda esclareceu sobre a soma do período rural com o período urbano, observando que "[...] pelo entendimento do INSS a soma do período rural mais o período urbano, o que caracteriza a aposentadoria híbrida, não é permitida, porém a Justiça tem entendimento diverso devido à ação civil pública, permitindo a soma para fins de carência" (DIÁRIO DE CAMPO, 2019b, p. 3). Ademais, disse que esse entendimento da via judicial se manterá enquanto permanecer a decisão da Ação Civil Pública, dando a entender que ela pode ser afastada a qualquer tempo (DIÁRIO DE CAMPO, 2019b).

O servidor refere-se à Ação Civil Pública de no 5038261-15.2015.4.04.7100, a qual foi autuada em 23/6/2015 na 25a Vara Federal de Porto Alegre/RS, tendo como autor o Ministério Público Federal e como réu o Instituto Nacional do Seguro Social (INSS). O Tribunal Regional Federal da 4ạ Região entendeu que o segurado possui direito à aposentadoria híbrida ao utilizar o período das atividades rurais e urbanas para fins do cumprimento da carência, bem como que os períodos anteriores à Lei $n^{\circ} 8.213 / 91$ serão contabilizados independentemente de recolhimento de contribuições (BRASIL, 2017d).

Durante o diálogo com o interlocutor da Agência do INSS indagou-se sobre a autarquia promover alguma política de conscientização dos direitos previdenciários com relação aos indígenas. Segundo o servidor, como a região do Vale do Taquari não possui grande população de indígenas, ${ }^{1}$ o INSS acaba não promovente esse tipo de ação por ali. Esclarece, contudo, que tem conhecimento desse tipo de política em âmbito nacional para todos os segurados (DIÁRIO DE CAMPO, 2019b), o que novamente reforça o entendimento de que a conscientização deve ser feita para todos os segurados e especialmente para o segurado indígena, uma vez que se trata de direitos complexos que mudam constantemente.

O servidor também foi questionado se ele teria conhecimento de alguma parceria entre a Funai e o INSS que facilitasse o acesso dos indígenas aos direitos da Previdência Social. Durante o diálogo o interlocutor afirmou não ter conhecimento de uma parceria do INSS diretamente com a Funai, porém, atualmente, têm acontecido algumas mudanças com relação à obtenção de dados dos segurados (DIÁRIO DE CAMPO, 2019b). Segundo ele, "[...] a partir da mudança o INSS tem tido acesso a todas as informações a nível federal do segurado e que, provavelmente, a Funai também tem" (DIÁRIO DE CAMPO, 2019b, p. 3).

Por fim, o servidor contribuiu explicando que apesar de os índios serem considerados segurados especiais em razão de suas atividades serem semelhantes aos agricultores e pescadores, os indígenas ainda são menos assistidos. Esclarece que os agricultores e os pescadores são filiados aos seus respectivos sindicatos, os quais os auxiliam em questões burocráticas e, inclusive, possuem acesso às diversas informações que facilitam no momento do requerimento. $O$ interlocutor do INSS relata, ainda, a função do sindicato, que reúne os documentos necessários, facilitando a análise do pedido do segurado (DIÁRIO DE CAMPO, 2019b).

A pesquisa com o servidor do Instituto Nacional do Seguro Social (INSS) de Lajeado/RS foi de suma importância para o presente estudo, pois se tratou de um interlocutor que, como funcionário público, está ligado com os direitos da Previdência Social diariamente. Os dados de campo corroboraram para demonstrar como ocorre na prática a análise dos benefícios previdenciários, principalmente com relação ao indígena, os desafios que toda população encontra ao acessar seus direitos, além do relato acerca da assistência ao índio quanto ao seu enquadrado como segurado especial.

A justificativa do servidor do Instituto Nacional do Seguro Social - INSS - acerca da baixa população indígena na região merece maior esclarecimento. Veja-se que na Aldeia Foxá/Lajeado há em torno de 128 pessoas, na aldeia Jamã Tÿ Tãnh, localizada no município de Estrela, há quase 200 indígenas. Além disso, devemos considerar também a aldeia Pó Mág/Tabaí, cuja quantidade de habitantes é de aproximadamente de 10 a 15 pessoas, bem como um acampamento temporário localizado em direção a Bom Retiro do Sul com cerca de 50 pessoas. Assim, considerando os indígenas de Lajeado e dos municípios próximos, percebe-se que eles representam quantidade considerável de pessoas e, portanto, merecem alguma política de conscientização acerca dos direitos previdenciários. 


\section{CONCLUSÃO}

A pesquisa, conforme se observou, possuiu como temática a abordagem do Direito Previdenciário com relação aos indígenas. Retomando a problemática proposta, vale salientar que o estudo buscou analisar relatos de um profissional que atende diariamente requerimentos de benefícios da Previdência Social para identificar quais os desafios do acesso aos direitos da Previdência Social na comunidade Kaingang Foxá.

A partir da narrativa do interlocutor do Instituto Nacional do Seguro Social (INSS) evidenciou-se que os indígenas podem encontrar dificuldades ao tentar acessar os direitos da Previdência Social em razão da falta de políticas públicas que os conscientizem acerca de seus direitos, pois se trata de um grupo vulnerável na sociedade. Da mesma forma, deve ser considerado que o desconhecimento sobre a cultura Kaingang e dinâmica indígena pelos não índios pode intensificar o preconceito existente na sociedade. Conforme informado, não existe benefício previdenciário destinado especificamente aos indígenas, muito menos qualquer outro benefício que possa ser considerado um privilégio em razão de sua identidade étnica.

Cumpre ressaltar que os povos indígenas, historicamente, foram relegados às condições de vulnerabilidade social pelo Estado brasileiro, muito embora tenham atuado como protagonistas e suportado imposições dos não índios há praticamente seis séculos. Assim, em que pese, seja evidente, a evolução dos direitos com relação aos povos indígenas após muita luta social e a Constituição de 1988, é possível identificar que os referidos direitos enfrentam muitas dificuldades para se tornarem de fato eficazes.

Dessa forma, é importante que o Estado de fato proporcione a garantia de todos os dispositivos que regulam questões indígenas, fortaleça as ações afirmativas e proteja esses povos que passaram parte de sua história e ainda passam lutando para afirmar seus direitos. Para isso, um dos pontos importantes é que se incentive a representatividade indígena no Parlamento brasileiro, pois, conforme demonstrado, a representatividade ainda é considerada baixa com relação à quantidade de índios existentes na população brasileira. Esse fato pode contribuir para que esses povos se incluam e passem a influenciar em decisões que afetam suas comunidades, bem como garanta a efetividade dos dispositivos que regulamentam seus interesses.

Vale relembrar, segundo o servidor do INSS com quem estabelecemos interlocução, que não há políticas públicas promovidas pela autarquia a fim de conscientizar a população indígena com relação aos seus direitos previdenciários. A região é conhecida pela presença de indígenas, assim, totalmente equivocada a justificativa de que a falta de ações por parte das autoridades ocorre em razão de poucos índios presentes na sociedade de Lajeado. Somente na Aldeia Foxá há 128 pessoas, devendo-se considerar, ainda, as aldeias da redondeza, como a aldeia de Estrela, que possui em torno de 200 pessoas, de Tabaí, que possui de 10 a 15, do acampamento em Bom Retiro do Sul, que conta com a presença de 50 indígenas aproximadamente, Porto Alegre, entre outros municípios do Estado que possuem presença de comunidades indígenas. É necessário, portanto, que as autoridades se voltem para as comunidades indígenas e promovam políticas públicas além de garantir as ações afirmativas para conscientizá-los de seus direitos, sem que deixem de respeitar sua cultura e dinâmica.

\section{REFERÊNCIAS}

BECKER, Ítala Irene Basile. O índio no Rio Grande do Sul. Aspectos arqueológicos, históricos, etnográficos e étnicos. Biênio da colonização e imigração. Porto Alegre: Comissão Executiva de Homenagem ao Índio, 1975. p. 97-123.

BRASIL. Constituição da República Federativa do Brasil. 1988. Disponível em: http://www.planalto.gov.br/ccivil_03/constituicao/constituicaocompilado.htm. Acesso em: 15 maio 2019.

BRASIL. Decreto no 3.048/99. Regulamento da Previdência Social. 1999. Disponível em: http://www.planalto.gov.br/ccivil_03/ decreto/D3048.htm. Acesso em: 27 set. 2019.

BRASIL. Fundação Nacional do Índio - Funai. Direitos sociais. Entre 2000 e 2019. Disponível em: http://www.funai.gov.br/index.php/nossas-acoes/direitos-sociais. Acesso em: 15 maio 2019a.

BRASIL. Fundação Nacional do Índio - Funai. Previdência social. Entre 2000 e 2019. Disponível em: http://www.funai.gov.br/ index.php/previdencia-social. Acesso em: 30 set. 2019b.

BRASIL. Instituto Brasileiro de Geografia e Estatística - IBGE. Censo demográfico 2010: Características gerais dos indígenas. Rio de Janeiro, 2012. Disponível em: https://biblioteca.ibge.gov.br/visualizacao/periodicos/95/cd_2010_indigenas_universo.pdf. Acesso em: 5 maio 2019.

BRASIL. Instituto Brasileiro de Geografia e Estatística - IBGE. Conheça cidades e Estados do Brasil. Panorama Lajeado, Rio Grande do Sul, 2019c. Disponível em: https://cidades.ibge.gov.br/brasil/rs/lajeado/panorama. Acesso em: 14 set. 2019. 
BRASIL. Instituto Nacional do Seguro Social - INSS. Forma de pagar e códigos de pagamento - segurado especial. Publicado em 2017a. Disponível em: https://www.inss.gov.br/servicos-do-inss/calculo-da-guia-da-previdencia-social-gps/forma-de-pagar-e-codigos-de-pagamento-segurado-especial/. Acesso em 19 out. 2019.

BRASIL. Instituto Nacional do Seguro Social - INSS. Instrução Normativa no 77, de 21 de janeiro de 2015. Diário Oficial da União, Brasília, DF, 2015a. Disponível em: http://www.in.gov.br/materia/-/asset_publisher/Kujrw0TZC2Mb/content/id/32120879/do1-2015-01-22-instrucao-normativa-n-77-de-21-de-janeiro-de-2015-32120750. Acesso em: 19 out. 2019.

BRASIL. Instituto Nacional do Seguro Social - INSS. Tipos de filiação. Publicado em 2017b. Disponível em: https://www.inss. gov.br/orientacoes/tipos-de-filiacao/. Acesso em 25 set. 2019.

BRASIL. Lei Complementar no 150 de 1o de junho de 2015. 2015b. Disponível em: http://www.planalto.gov.br/ccivil_03/leis/ Icp/lcp150.htm. Acesso em: 19 maio 2020.

BRASIL. Lei $n^{\circ}$ 8.213, de 24 de julho de 1991. Dispõe sobre os Planos de Benefícios da Previdência Social e dá outras providências. 1991. Disponível em: http://www.planalto.gov.br/ccivil_03/leis/l8213cons.htm. Acesso em: 20 set. 2019.

BRASIL. Lei no 12.023 de 27 de agosto de 2009. 2009. Disponível em: http://www.planalto.gov.br/ccivil_03/_Ato20072010/2009/Lei/L12023.htm. Acesso em: 19 maio 2020.

BRASIL. Secretaria de Previdência Ministério da Economia. O que é Previdência Complementar. Publicado em 2013. Modificado em 2018. Disponível em: http://www.previdencia.gov.br/a-previdencia/previdencia-complementar/o-que-previdncia-complementar/. Acesso em: 19 out. 2019.

BRASIL. Secretaria de Previdência Ministério da Economia. Regime Geral - RGPS. Publicado em 2013. Modificado em 2019d. Disponível em: http://www.previdencia.gov.br/perguntas-frequentes/regime-geral-rgps/. Acesso em: 19 out. 2019.

BRASIL. Secretaria de Previdência Ministério da Economia. Regime Próprio - RPPS. Publicado em 2013. Modificado em 2017c. Disponível em: http://www.previdencia.gov.br/perguntas-frequentes/regime-proprio-rpps/. Acesso em 19 out. 2019.

BRASIL. Tribunal Regional Federal da 4ạ Região - TRF4. Ação Civil Pública no 5038261-15.2015.4.04.7100. 2017d. Disponível em: https://eproc.trf4.jus.br/eproc2trf4/controlador.php?acao=acessar_documento_publico\&do$c=41497281557170221101858568479 \&$ evento $=490 \& k e y=3 e c 4 f 2 d e 00 d 8608691524 e 9562 d e 0 e-215767 c 8 c 95 f d 753 b 2 f 3 e-$ 2c89e0274b4e7\&hash=7b3ab0fe4184c04cf0cb49e0c9a77d29. Acesso em: 19 out. 2019.

CASTRO, Carlos, A. P.; LAZZARI, João B. Direito previdenciário. 1. ed. Rio de Janeiro: Forense, 2016. E-book. Disponível em: http://www.univates.br/biblioteca. Acesso em: 20 maio 2019.

CHEMIN, Beatris F. Manual da Univates para trabalhos acadêmicos: planejamento, elaboração e apresentação. 3. ed. Lajeado: Univates, 2015.

D’ANGELIS, Wilmar da Rocha. Portal Kaingang. A língua Kaingang. 2006. Disponível em: http://www.portalkaingang.org/Lgua_ Kaingang.pdf. Acesso em: 17 ago. 2019.

DIÁRIO DE CAMPO de 6/9/2019. Saída de Campo a Terra Indígena Foxá. Acervo do Acervo do Projeto. 6 set. 2019 a. 3 p.

DIÁRIO DE CAMPO de 11/10/2019. Saída de Campo a Terra Indígena Foxá. Acervo do Acervo do Projeto. 11 out. 2019 b. 3 p. DIÁRIO DE CAMPO de 16/9/2019. Saída de Campo a Terra Indígena Foxá. Acervo do Acervo do Projeto. 16 set. $2019 \mathrm{c} .1$ p.

FERREIRA, Bruno. Educação Kaingang: processos próprios de aprendizagem e educação escolar. 2014.99 f. Dissertação (Mestrado em Educação) - Universidade Federal do Rio Grande do Sul, Programa de Pós-Graduação em Educação, Porto Alegre, RS, 2014.

FREITAS, Eduardo M. de N. A seguridade social dos indígenas brasileiros à luz dos direitos humanos e fundamentais. 2016. Dissertação (Mestrado em Direito) - Universidade Federal do Ceará, Faculdade de Direito, Programa de Pós-Graduação em Direito, Fortaleza, CE, 2016.

GIL, Antônio C. Métodos e técnicas de pesquisa. 6. ed. São Paulo: Atlas, 2008.

GREGORY, Josemir José. Fazenda da Estrella: um estudo de caso envolvendo posse territorial e negociações no Sul do Brasil durante o século XIX. 2015. Monografia (Graduação curso de História) - Universidade do Vale do Taquari - Univates, Lajeado, dez. 2015.

LAJEADO (Município). Prefeitura de Lajeado. História do Município. 2019. Disponível em: https://www.lajeado.rs.gov.br/?titulo=Lajeado\&template=conteudo\&categoria=931\&codigoCategoria=931\&idConteudo=2963\&tipoConteudo=INCLUDE_MOSTRA_CONTEUDO. Acesso em: 10 set. 2019.

LAPPE, Emilí; LAROQUE, Luis F. S. Terra indígena Foxá "aqui no cedro": passado e presente Kaingang na sociedade do Vale do Taquari-RS-BR. In: Geousp, Espaço e Tempo (on-line), v. 22, n. 1, p. 025-042, jun. 2018. ISSN 2179-0892. Disponível em: http:// www.revistas.usp.br/geousp/article/view/125928. Acesso em: 17 abr. 2019.

MOTA, Lúcio Tadeu. A denominação kaingang na literatura antropológica, histórica e lingüística. In: TOMMASINO, Kimiye; VEIGA, Juracilda; NOELLI, Francisco Silva (org.). Novas contribuições aos estudos interdisciplinares dos Kaingang. Londrina: Eduel, 2004.

NONNENMACHER, Marisa S. Aldeamentos Kaingang no Rio Grande do Sul: século XIX. Porto Alegre: EDIPUCRS, 2000. 
OLIVEIRA, Marilda D. Essa terra já era nossa: um estudo histórico sobre o grupo Kaingang na cidade de Lajeado, Rio Grande do Sul. Lajeado: Univates, 2010.

PRESTES, Fabiane S.; LAROQUE, Luis F. S. O saber sensível do Kujà sobre ambiente e saúde: um estudo de caso da Comunidade Indígena Foxá de Lajeado/RS. In: Fronteiras: Journal of Social, Technological and Environmental Science. v. 7, n.3, p. 342-356, dez. 2018. Disponível em: http://periodicos.unievangelica.edu.br/index.php/fronteiras/. Acesso em: 17 mar. 2019.

SANTOS, Marisa F. Direito previdenciário esquematizado. 6. ed. São Paulo: Saraiva Educação, 2016. E-book. Disponível em: https://integrada.minhabiblioteca.com.br/\#/books/9788553601356/cfi/0!/4/2@100:0.00. Acesso em: 10 maio 2019.

SANTOS, Marisa F. Direito previdenciário esquematizado. 8. ed. São Paulo: Saraiva Educação, 2018. E-book. Disponível em: https://integrada.minhabiblioteca.com.br/\#/books/9788553601356/cfi/0!/4/2@100:0.00. Acesso em: 17 maio 2019.

TOMMASINO, Kimiye; FERNANDES Ricardo Cid. Povos indígenas no Brasil. 2001. Instituto Sócio Ambiental. Disponível em: https://pib.socioambiental.org/pt/Povo:Kaingang\#Cosmologia_e_mitologia Acesso em: 17 ago. 2019.

VEDOY, Moisés llair Blum. Sesmarias, fazendas, desenvolvimento e desdobramentos socioambientais em territórios da bacia hidrográfica do Rio Taquari de meados do século XVIII a meados do século XIX. 2018. Dissertação (Mestrado em Ambiente e Desenvolvimento) - Universidade do Vale do Taquari - Univates, Lajeado, RS, dez. 2018. Disponível em: https://www.univates. br/bdu/. Acesso em: 4 nov. 2019.

VEIGA, Juracilda. Cosmologia Kaingang e suas práticas rituais. In: TOMMASINO, Kimiye; MOTA, Lúcio Tadeu; NOELLI, Francisco Silva (org.). Novas contribuições aos estudos interdisciplinares dos Kaingang. Londrina: Eduel, 2004.

VEIGA, Juracilda. Portal Kaingang. Economia Kaingang. 2006. Disponível em: http://www.portalkaingang.org/index_cultura_5_1.htm. Acesso em: 17 ago. 2019. 